\title{
Pembuatan Learning Management System (LMS) berbasis Moodle untuk Lembaga Bahasa Inggris Supple English Lessons (SPELLs)
}

\author{
Nicky Rosadi*, Hamzah Robbani, Windi Megayanti, Hapsari Widayani \\ Universitas Indraprasta PGRI \\ nicky.rosadi@unindra.ac.id
}

\begin{abstract}
Abstrak
Sesuai surat edaran dinas Pendidikan No. 4 Tahun 2020 terkait Pembelajaran pada Masa Pandemi Covid-19, Lembaga Bahasa Inggris Supple English Lessons (SPELLs) melakukan pengembangan metode pembelajaran melalui metode daring yang dalam hal ini didampingi oleh tim pengabdian kepada masyarakat dari Universitas Indraprasta PGRI. Tim abdimas melakukan pembuatan learning management system (LMS) berbasis Moodle yang disesuaikan dengan kebutuhan di Lembaga Bahasa Inggris Supple English Lessons (SPELLs). Hasil dari abdimas ini, Lembaga Bahasa Inggris Supple English Lessons (SPELLs) dapat menyelenggarakan pembelajaran dan tes kemampuan berbahasa Inggris setara TOEFL ITP melalui learning management system (LMS) berbasis Moodle.
\end{abstract}

Kata Kunci: tes kemampuan berbahasa Inggris setara TOEFL ITP, learning management system (LMS), Moodle, Supple English Lessons (SPELLs)

\section{Creating a Moodle-based Learning Management System (LMS) for English Language Institutions Supple English Lessons (SPELLs)}

\begin{abstract}
According to the circular letter of the Department of Education No. 4 of 2020 related to Learning during the Covid-19 Pandemic, the English Language Institute Supple English Lessons (SPELLs) developed learning methods through online methods which in this case were accompanied by a community service team from Indraprasta University PGRI. The abdimas team developed a Moodle-based learning management system (LMS) that was tailored to the needs of the Supple English Lessons (SPELLs) English Language Institute. As a result of this service, the English Language Institute Supple English Lessons (SPELLs) can organize learning and English language proficiency tests equivalent to TOEFL ITP through a Moodle-based learning management system (LMS).
\end{abstract}

Keywords: English proficiency test equivalent to TOEFL ITP, learning management system (LMS), Moodle, Supple English Lessons (SPELLs)

\section{PENDAHULUAN}

Sudah terdapat beberapa penelitian yang mengemukakan bahwa adanya efektivitas pembelajaran dengan metode daring. Terdapat perbedaan signifikan pada hasil pretest dan post-test setelah diberikan pembelajaran melalui web blog (Khusniyah \& Hakim, 2019). Pada pengabdian masyarakat ini, tim abdimas melakukan pembuatan pembelajaran daring dengan sebuah aplikasi web base yang bernama Moodle. Moodle merupakan aplikasi yang tersedia pada layanan server yang dapat digunakan oleh sekolah untuk membangun pembelajaran berbasis daring. Dengan Moodle ini tim abdimas membuat sebuah ruang 
Vol. 1, No. 3,

November

2020

pp. 193-197

e-ISSN

2722-2004

Title

Creating a

Moodle-based

Learning

Management

System (LMS)

for English

Language

Institutions

Supple English

Lessons

(SPELLs)

Author

N. Rosadi,

H. Robbani,

W. Megayanti,

H. Widayani

belajar virtual atau sering juga disebut learning management system yang mampu memberikan penyampaian materi dalam bentuk slide, modul, video, kuis, hingga presensi.

Moodle merupakan aplikasi yang valid, praktis, dan efektif (Samala, Fajri, \& Ranuharja, 2019), dari segi presensi guru dapat melakukan pengaturan jam akses dan keterlambatan siswa saat dilaksanakannya pembelajaran, lalu pada saat ingin merekap presensi guru juga dapat langsung menarik rekap data pada aplikasi Moodle. Penggunaan Moodle ini juga telah diaplikasikan pada pembelajaran di Pusat Kegiatan Belajar Masyarakat (PKBM) Smart Bangun Negeri (Robbani, Rosadi, \& Nurfitria, 2020). Dalam pembelajaran, tutor dapat memasukkan berbagai media belajar dengan fitur-fitur yang tersedia pada Moodle. Dengan ini diharapkan para tutor dapat memberikan pembelajaran yang efektif. Pada sesi penilaian, tim abdimas juga menambahkan fitur kuis dan otomasi input soal dengan template. Sehingga tutor dapat menginput soal tes kemampuan berbahasa Inggris setara dengan TOEFL ITP yang biasa dilakukan menggunakan kertas. Pada akhirnya tes kemampuan berbahasa Inggris dapat dilakukan secara daring penuh tanpa harus menggunakan kertas dan datang ke lembaga.

\section{METODE PELAKSANAAN}

Tim abdimas melakukan observasi dan identifikasi pada rencana dalam pembuatan learning management system (LMS) berbasis Moodle. Mengacu pada SKKNI No. 161 tahun 2015 Tentang Standard Kompetensi Kerja bidang Pelatihan. Dengan mengacu pada SKKNI, pembuatan daring untuk mendukung pembelajaran ini menjadi terstandar dan auditable. Pada pembuatan RBV di institusi lainnya dapat menggunakan metode pengembangan ADDIE Model. ADDIE memiliki tahapan yang sistematis, dan lebih rasional yaitu terdiri dari lima tahap: analysis, design, development, implementation, evaluation (Samala et al., 2019).

Pembuatan learning management system (LMS) berbasis Moodle meliputi program pembelajaran dan tes yang di dalamnya terdapat kelas pretest untuk mengetahui kemampuan berbahasa Inggris siswa sebelum mengikuti pembelajaran, kelas pembelajaran yang terdiri atas tiga tingkatan; basic, intermediate, advance, serta kelas Prediction for English Test (POETs). Total waktu pembuatan learning management system (LMS) berbasis Moodle pada Lembaga Bahasa Inggris Supple English Lessons (SPELLs) ialah satu bulan.

Pembuatan learning management system (LMS) berbasis Moodle pada Lembaga Bahasa Inggris Supple English Lessons (SPELLs) dilaksanakan secara WFH (work from home) oleh masing-masing personel secara koordinatif. Pada minggu pertama, dilakukan analisis kebutuhan selama satu minggu. Satu minggu berikutnya, tim mendesain learning management system (LMS) sesuai kebutuhan mitra. Pembuatan, implementasi, dan evaluasi memakan waktu hingga dua minggu. Peralatan yang digunakan oleh tim di antaranya laptop, alat tulis, dan paket data internet.

\section{HASIL DAN PEMBAHASAN}

Hasil kegiatan pembuatan learning management system (LMS) berbasis Moodle pada Lembaga Bahasa Inggris Supple English Lessons (SPELLs) ini 
memberikan pengalaman tersendiri bagi para tutor dan manajemen lembaga. Hal-hal yang biasa dilakukan dengan menggunakan metode klasik yaitu; mengajar tatap muka dan tes berbasis kertas, kini tidak perlu lagi dilakukan. Para tutor bahkan dapat menyelenggarakan pembelajaran dan tes hanya melalui rumah masing-masing.

Mengacu pada SKKNI No. 161 yang khususnya pada kode unit P.854900.015.01 yaitu Mendesain Lingkungan Belajar Virtual. Tim abdimas akan melaksanakan serangkaian kegiatan yang termaktub dalam gambar berikut.

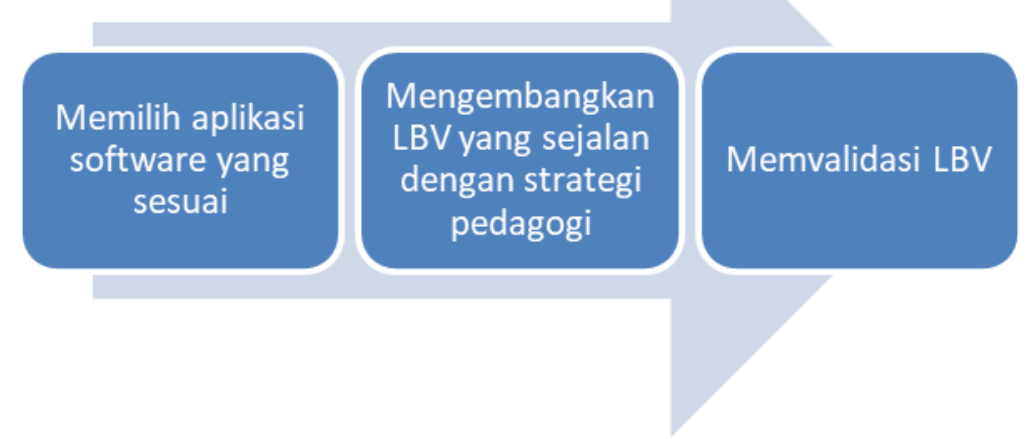

Gambar 1. Bagan alur proses kegiatan validasi LBV

Proses penentuan aplikasi diobservasi oleh tim abdimas. Pembelajaran diidentifikasi menggunakan metode asynchronous. Metode asynchronous merupakan gaya belajar kolaboratif, sekelompok siswa bertemu dengan tutor melalui internet dan dapat berkomunikasi, namun tidak selalu online pada waktu yang sama. Siswa dapat berkomunikasi dengan meninggalkan pesan yang dapat direspons selang beberapa waktu (Rohman, Informatika, Teknik, \& Lamongan, 2020). Aplikasi Moodle dapat mengakomodasi kebutuhan belajar asynchronous dengan skema tutor memberikan pembelajaran dan pembelajaran dapat dilakukan kapan saja serta di mana saja. Hal tersebut diperlukan karena tutor dan siswa dari Lembaga Bahasa Inggris Supple English Lessons (SPELLs) memiliki aktivitas beragam, dari pekerja aktif, ibu rumah tangga, hingga anak usia sekolah.

Moodle dapat memberikan sentuhan pembelajaran secara klasikal dan individual. Saat perlu dilaksanakan diskusi dan pembelajaran sycnrhonous, siswa dan tutor dapat menggunakan forum diskusi. Dalam fitur forum diskusi, tutor dapat memberikan materi dengan attachment pdf, ppt, dll. Begitu pula siswa yang dapat merespons materi dengan kolom komentar, attachment dokumen $p d f$, ppt, doc, dll. Pada fitur tersebut tutor dapat memberikan penilaian dan melakukan pembatasan waktu. Fitur forum diskusi menjadikan wadah guru dalam pembelajaran online sama layaknya pembelajaran klasikal. Hanya saja, tidak bertatap muka.

Pada pembelajaran individual, tutor dapat memberikan forum obrolan dan kuis. Forum obrolan diberikan saat siswa membutuhkan konsultasi materi tertentu, lalu kuis untuk mengukur penilaian siswa secara individual. Hal tersebut sejalan dengan penelitian yang dilakukan oleh Salama et al., (2019) bahwa dari kondisi riil yang dialami satuan pendidikan di antaranya keterbatasan waktu dan tempat, keterbatasan materi, sulitnya pembelajaran secara individual, serta kurangnya inovasi dapat dicapai dengan aplikasi Moodle yang dapat mengakomodasi kekurangan-kekurangan tersebut.

Setelah penentuan LBV dengan aplikasi Moodle, tim abdimas melaksanakan pengembangan LBV dengan menerapkan tahap-tahap berikut: 
Vol. 1, No. 3, November 2020

pp. $193-197$ e-ISSN:

2722-2004

Title

Creating a

Moodle-based

Learning

Management

System (LMS)

for English

Language

Institutions

Supple English

Lessons

(SPELLs)

Author

N. Rosadi,

H. Robbani,

W. Megayanti,

H. Widayani

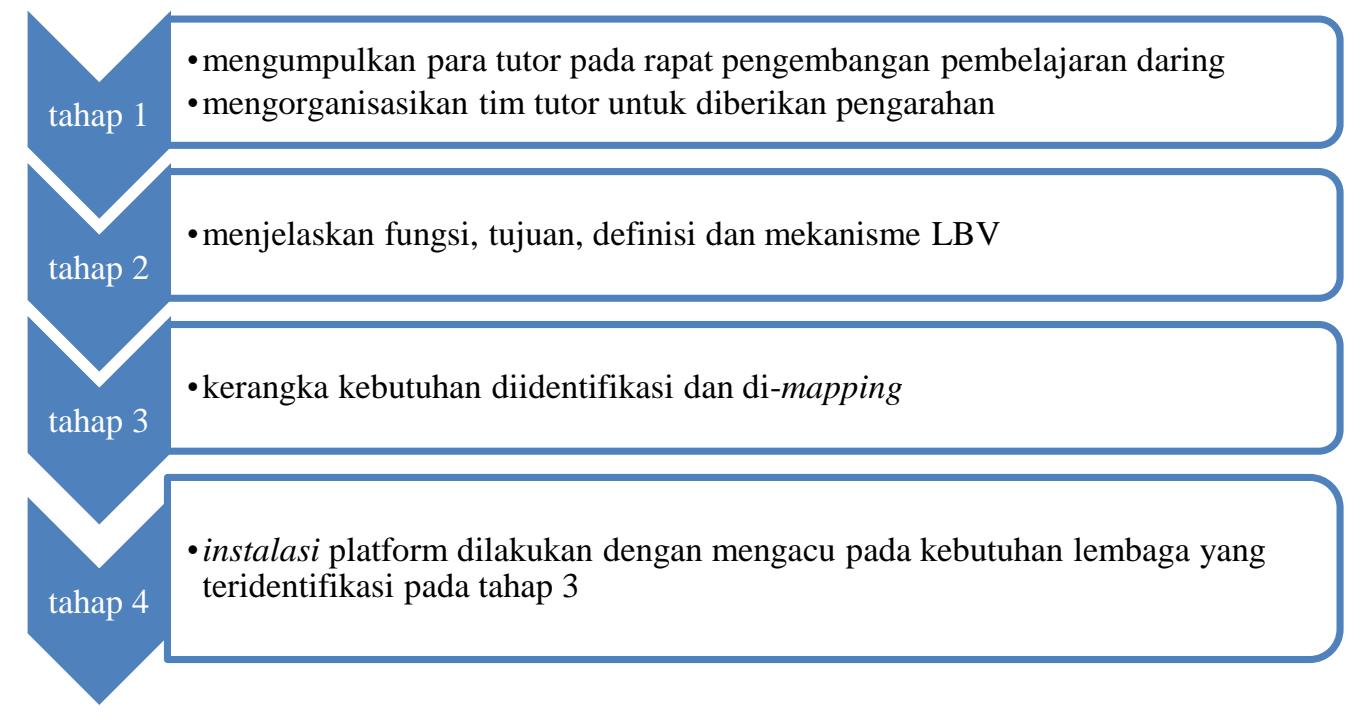

Gambar 2. Bagan alur proses pengembangan LBV

Proses selanjutnya tim abdimas melaksanakan validasi LBV dengan melakukan uji coba aplikasi pada proses pembelajaran serta tes dan melakukan perbaikan pada hal-hal yang perlu dikoreksi. Tim abdimas melakukan tindakan korektif pada tampilan tatap muka yang lebih mudah dibaca sehingga visibilitas meningkat. Hal tersebut dikarenakan pengguna terdapat dari beberapa golongan usia yang lebih suka font berukuran besar dan gambar yang mudah diakses.
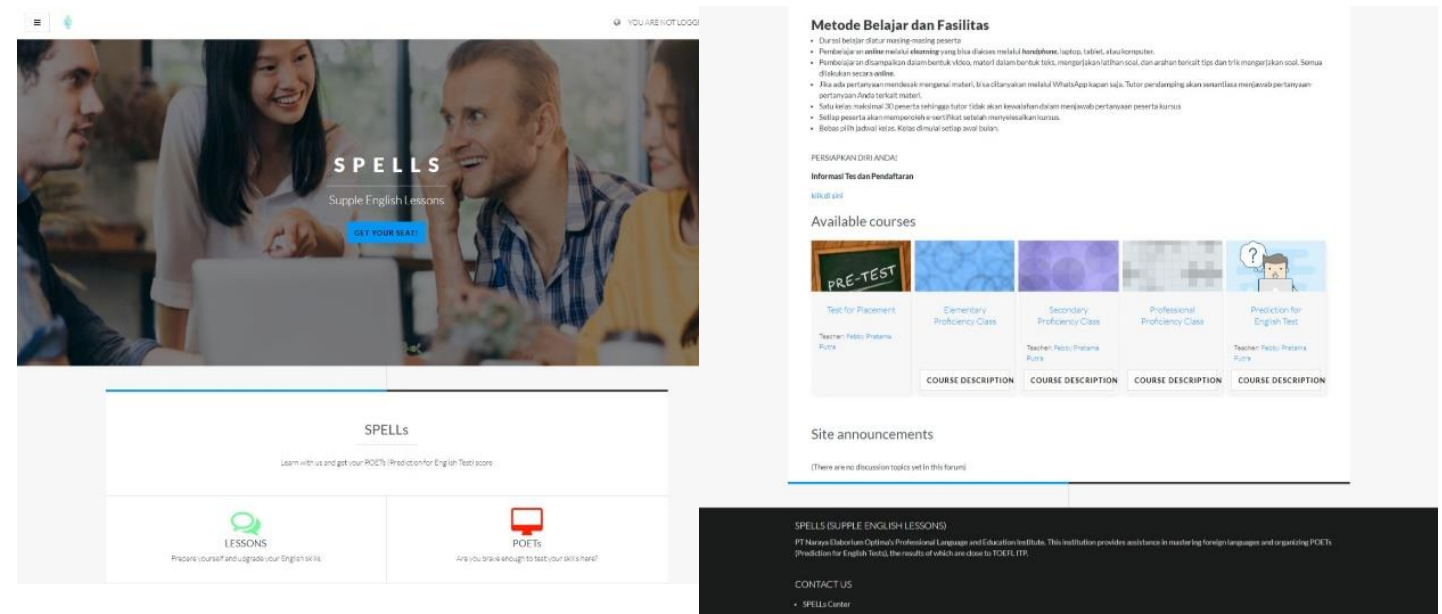

Gambar 3. Tampilan learning management system (LMS) berbasis Moodle yang dibuat untuk Lembaga Bahasa Inggris Supple English Lessons (SPELLs)

\section{SIMPULAN}

Pembuatan learning management system (LMS) berbasis Moodle pada Lembaga Bahasa Inggris Supple English Lessons (SPELLs) ini memiliki kesimpulan: 1. Terjawabnya permasalahan media pembelajaran lembaga pendidikan di masa pandemi Covid-19 yang mewajibkan pembelajaran dilakukan 
di rumah; 2. Penentuan aplikasi Moodle melalui serangkaian pertimbangan observasi dan identifikasi memberikan peluang bagi lembaga pendidikan untuk melaksanakan pembelajaran synchronous dan asynchronous system tanpa kendala waktu dan tempat; 3. Dengan kemudahan yang sudah ada, lembaga pendidikan diharapkan terus melakukan perbaikan dalam pembelajaran karena tim abdimas akan melaksanakan pemantauan dan supervisi demi penyelenggaraan pembelajaran daring yang terstandar.

\section{DAFTAR PUSTAKA}

Daniel, W.W. (1980). Statistika nonparametrik terapan. (Terjemahan Tri Kuntjoro). Jakarta: Gramedia.

Effendi, S. (1982). Unsur-Unsur Penelitian Ilmiah. Dalam Masri Singarimbun (Ed.). Metode penelitian survei. Jakarta: LP3ES.

Gronlund, N.E. \& Linn, R.L. (1990). Measurement and evaluation in teaching. $\left(6^{\text {th }} e d.\right)$. New York: Macmillan.

Hasdiansyah, A., \& Suryono, Y. (2016). Evaluasi Program Pelatihan Pemuda dalam Meningkatkan SDM di HMI Koordinator Komisariat UNM. Jurnal Pendidikan dan Pemberdayaan Masyarakat, 3(1), 115. doi:http://dx.doi.org/10.21831/jppm.v3i1.8062

Pritchard, P.E. (1992). Studies on The Bread-Improving Mechanism of Fungal Alpha-Amylase. Journal of Biological Education, 26 (1), 14-17.

Retnawati, H. (2014). Teori Respons Butir dan Penerapannya. Yogyakarta: Nuha Medika.

Robbani, H., Rosadi, N., \& Nurfitria, O. (2020). Creating a Learning Management System at the Smart Bangun Negeri Community Learning Activity Center. KANGMAS: Karya Ilmiah Pengabdian Masyarakat, 1(2), 75-78. https://doi.org/10.37010/kangmas.v1i2.52

Suyanto, S. (2009). Keberhasilan Sekolah dalam Ujian Nasional Ditinjau dari Organisasi Belajar. Disertasi, tidak dipublikasikan. Universitas Negeri Jakarta. 